\title{
Contraceptive use, knowledge, attitude, perceptions and sexual behavior among female University students in Uganda: a cross-sectional survey
}

\author{
Henry Nsubuga ${ }^{1 * \dagger}$, Juliet N. Sekandi ${ }^{2,3+}$, Hassard Sempeera ${ }^{2}$ and Fredrick E. Makumbi ${ }^{2}$
}

\begin{abstract}
Background: In Uganda, the risk of unintended pregnancies and unsafe abortions remains high due to relatively low contraceptive use. There is paucity of data on knowledge, attitudes, perceptions and practices towards modern contraceptives and, sexual and reproductive health especially among the young female university students.

Methods: A survey was conducted at Makerere University main campus in Kampala, Uganda during April 2014. A team of well-trained and experienced research assistants interviewed female undergraduate students who provided data on socio-demographic characteristics, knowledge, perceptions and attitudes and use of contraceptives, as well as other sexual and reproductive health practices. Users of any contraceptive method in the past 12 months were coded as ' 1 ' and none users as ' 0 '. The prevalence of contraceptive use was determined as the number of users divided by all female participants. Prevalence ratios (PRs) with their corresponding $95 \%$ confidence intervals were used as measures of association between contraceptive use and associated factors. The PRs were obtained via a modified Poisson regression model using a generalized linear model with Poisson as family and a log link without an offset but including robust standard errors. All analyses were conducted with Stata version 13.

Results: A total of 1,008 females responded to the survey; median (IQR) age was 21(20, 21) years, $38.6 \%$ in year 2 of study, and nearly three quarters (72.3\%) were of Christian faith. Knowledge of any contraceptives was almost universal (99.6\%) but only $22.1 \%$ knew about female condoms. Perceived acceptability of contraceptive use at the university (93\%) or being beneficial to male partners too (97.8\%) were high. Nearly $70 \%$ had ever engaged in sexual intercourse and $62.1 \%$ reported sexual intercourse in the past 12 months. Overall, $46.6 \%$ reported current contraceptive use, with male condoms (34.5\%) being the commonest methods. Factors associated with higher contraceptive use were being in year 2, consensual union or perception that contraceptives are for females only. However, being evangelical/SDA or perception that contraceptive use is wrong was associated with lower contraceptive use. Overall, $9 \%$ reported ever being pregnant, $2 \%$ were pregnant at the time of the survey and a third (33.8\%) knew of a pregnant friend. About 40 $\%$ of ever pregnant respondents reported ever trying to terminate the pregnancy.
\end{abstract}

Conclusions: Knowledge, perceived acceptability and benefits of contraceptive use were nearly universal, but contraceptive use was suboptimal in this setting. Ever trying to terminate a pregnancy was common and a clear indicator of unintended pregnancies.

Keywords: Contraceptives, Female undergraduates, Knowledge, Attitudes, Perceptions

\footnotetext{
* Correspondence: nsubugahl@gmail.com

${ }^{\dagger}$ Equal contributors

${ }^{1}$ Makerere University, Counseling and Guidance Centre, Kampala, Uganda

Full list of author information is available at the end of the article
} 


\section{Background}

The proportion of young women reporting unintended pregnancy and unmet need for contraception remains high in developing countries [1]. Unintended pregnancies are associated with increased risk of unsafe abortions, maternal morbidity and mortality [2]. In order to avert the unintended pregnancies and consequent adverse outcomes, contraceptive use has been prioritized as a key intervention [3]. Improving the universal access to sexual and reproductive health services including contraceptives was a key target of the Millennium Development Goals (MDG) [4, 5].

In developing countries, one in three women give birth before the age of 20 and pregnancy-related death during child birth is two times higher compared to women older than 20 years [5]. A quarter of the estimated 20 million unsafe abortions and 70,000 related deaths each year occur among women aged 15-19 years [5]. In sub-Saharan Africa alone, it is estimated that 14 million unintended pregnancies occur every year, with almost half occurring among women aged 15-24 years [6]. It is evident that use of effective contraceptive methods would potentially prevent 90 $\%$ of abortions, $20 \%$ pregnancy-related morbidity and a third (32\%) of maternal deaths worldwide [4].

In Uganda, an estimated 1.2 million unintended pregnancies occurred in 2008, representing more than half of the country's 2.2 million pregnancies [2]. The risk of pregnancy increases with a widening gap between sexual debut and age of first marriage [7, 8]. In Uganda nearly two thirds (64\%) of women aged 25-49 years reported early sexual debut before the age of 18 years [9]. At the time of enrolling into Universities, women are at an age of about two years above the median age of sexual debut in Uganda suggesting that they are usually sexually active.

Overall, the use of contraceptives is not openly discussed among young unmarried women due to strong cultural and religious beliefs, which exposes the young women to the increased risk of unwanted/unintended pregnancies. In many African traditional culture settings, pregnancy before marriage is often viewed as an abomination. As such, many unmarried females who get unintended pregnancies seek abortions services for fear of societal judgment. Abortion in Uganda being illegal increases the risk of maternal deaths because it is usually unsafe and at times conducted by traditional herbalists.

According to the two major surveys conducted among university students in Uganda, findings indicated that students did not have access to sexual and reproductive health services and HIV/AIDS-related programmes despite their engagement in high-risk sexual behaviours [10, 11]. Findings also showed that a quarter (25\%) of the university students had unmet need for contraceptives yet their level of awareness about contraceptives was high [1, 12]. Knowledge, attitudes and perceptions (KAP) about sexual and reproductive health may influence contraceptive use suggesting that interventions based on KAP may lead to reduced rates of unintended pregnancies [13].

This study was motivated by the continued anecdotal reports showing a common occurrence of unintended pregnancies and sexually transmitted infections among students seeking services at the University's Counseling and Guidance Centre. However, there was paucity of data on the knowledge, attitudes, and perceptions, access to and use of contraceptives and sexual and reproductive health services/information among Makerere University female students. Data generated from this study will inform and enhance the design of studentcentered programs to improve contraceptive knowledge and use, and thus potentially avert the unintended pregnancies and the consequent adverse outcomes in teaching institutions such as Makerere University.

\section{Methods}

\section{Design, study setting and population}

Across-sectional survey was conducted among female undergraduate students at Makerere University main campus. Makerere University is the oldest and largest public institution of higher education in Uganda. The University offers both undergraduate and graduate programs to approximately 40,000 students, half of who are females. The main university campus is located about $2.5 \mathrm{~km}$ from the capital city, Kampala.

Data were collected from April $1^{\text {st }}$ to April $30^{\text {th }} 2014$ among 1,008 students selected on the basis of halls of residence using quantitative data collection tools. All registered undergraduate students aged 18-30 years were eligible to participate in the study. Some female students resided at the three halls of residence at the main campus while majority resided off-campus at private hostels and a few were commuting from their parents'/guardians' homes.

The study outcomes included knowledge, perception/attitudes towards contraception, and reported contraceptive use in the 12 months following the survey. The independent variables were age, year of study, religion/faith, marital status and source of health information about family planning services and commodities.

Knowledge was defined as the state of awareness of contraceptive methods, any specific types and the source of contraceptives. Attitude or perception was defined as respondent's opinion or view, whether positive or negative towards a practice or behavior such as contraceptive use. Knowledge was operationalized based on the following question "Have you ever heard about contraceptives?" Affirmative responses (yes) led to subsequent questions on the reasons for use of contraceptives, methods and the sources known to her. Then the respondent was considered knowledgeable if they correctly provided responses based on the listed options on the tool. The perceptions/attitudes 
of respondents about contraceptives were assessed using a 5 point-likert scale consisting of a range of responses from strongly agree (1), agree (2), neutral (3), disagree (4) and strongly disagree (5). Statements such as "It is not easy for me to discuss with my partner about sexual matters", "Family planning is for females only and not males", "Family planning is acceptable in our community" were used to elicit respondent's views/options so as to determine their perceptions or attitudes towards family planning.

\section{Sample size estimation}

A total of 973 female students were estimated as the appropriate sample size for this survey using the modified Kish-Leslie formula (Leslie Kish, 1965) for cross sectional studies. The sample size determination assumed $21.5 \%$ of female students using modern contraceptives, a $5 \%$ margin of error for the estimated p, $95 \%$ confidence interval around the estimates, a design-effect of 3 to account for multistage sampling conducted through use of residential halls as clusters, and a survey response rate of $80 \%$. However, a total of 1,008 students were interviewed creating an excess of 35 respondents because interviews were conducted simultaneously at the multiple sites within the University.

\section{Participant recruitment}

The initial participant recruitment plan included a sampling frame of about 22,000 female registered students as of April 2014, which was obtained from the university academic registrar's office. The list included each student's assigned hall of residence, year of study, faculty where registered for the studies, and telephone contacts. A sample of 973 students was randomly selected from this sampling frame. However, only eighty-five students could be reached via the registered telephone contacts. Reasons for none accessibility was primarily due to incorrectly registered telephone numbers or use of the next of kin telephone number who was not aware of the student's whereabouts at the time of the survey. Although three callbacks were conducted, this approach did not result into any improvement in response rates. The research team thereafter made a protocol amendment to recruit participants using convenience sampling. Interviewers were therefore assigned or stationed at the various academic units within the university during daytime ( 8 hours) to request students to participant in the study.

\section{Data collection and quality assurance}

The data collection tools were pre-tested and the study protocol piloted using twenty (20) questionnaires at a university within Kampala with similar characteristics as Makerere University. Research assistants/Interviewers were trained in data collection, research ethics, interviewer skills, seeking and administering informed consent. All the interviewers were graduates because the undergraduate participants were perceived to respond to persons who were senior in academic training. The interviews were conducted in English which both the interviewers and participants were knowledgeable. All completed questionnaires were reviewed by the field supervisors and checked for completeness by data editor at Makerere University School of Public Health data management centre. Interviewers were only allowed to interview another respondent after the field supervisor had completed reviewing the completed questionnaire.

\section{Ethics statement}

This study was reviewed and received ethical approval from the Higher Degrees Research and Ethics Committee at Makerere University School of Public Health and the Uganda National Council for Science and Technology. Permission to conduct the study was granted by the Makerere University administration. Written informed consent was obtained from all study participants.

\section{Statistical analysis}

Exploratory data analysis was conducted on all key variables. Descriptive statistics were generated with proportions (or percentages) for categorical data, and mean (standard deviation) for normally distributed data or median (inter-quartile range) if continuous data were skewed. Also bar graphs for categorical data such as reported contraceptive use by year of study were constructed. The main outcome of this study was current use of any contraceptive method, measured as a binary variable: "non-users" coded as "0" or "users" coded as " 1 ". Current use of contraception was calculated as the proportion of students who reported to have used any method of contraception in the past 12 months prior to the survey. Cross tabulations of knowledge, perceptions and attitudes towards contraceptive use and sexual behavior stratified by year of study were generated. The prevalence of contraceptive use was determined as the number of users divided by all female participants. Prevalence ratios (PRs) with their corresponding 95 $\%$ confidence intervals were used as measures of association between contraceptive use and associated factors. The PRs were obtained via a modified Poisson regression model using a generalized linear model with Poisson as family and a log link without an offset but including robust standard errors. The log-binomial model could not converge to provide an estimate of the PRs. Odds ratio could not be used as a measure of association because of the potential to overestimate the effect due to the high prevalence of the primary outcome. The year of study was considered as the main exposure variable, and adjusted for other variables including age, marital status, residence of student, religion, history of pregnancy and, beliefs and attitudes about contraceptives as potential confounders. All statistical analyses 
were performed in Stata version 12.1 (Statacorp, College Station. Texas).

\section{Results}

Table 1 shows the characteristics of the study participants. A total of 1008 students were enrolled in the study. The recruitment of participants at the multiple independent academic units resulted into 35 extra participants, which was reported to the Institutional Review Board (IRB) as a protocol deviation. The mean (SD) age was 21.7 (2.3) years, with majority (87.5\%) aged $20-24$ years, $38.6 \%$ in year 2 of study, and Christian faith (Catholics $33.6 \%$, protestant $38.7 \%$ ) as the major reported religion. Most students were not married ( $87 \%)$, just over a third (36.6 \%)

Table 1 Baseline Characteristics of 1008 Female University Students, April 2014

\begin{tabular}{|c|c|c|}
\hline Characteristics & Number & Percent, $\%$ \\
\hline Total & $1,008^{*}$ & 100 \\
\hline \multicolumn{3}{|l|}{ Age category } \\
\hline $18-19$ & 65 & 6.4 \\
\hline $20-24$ & 882 & 87.5 \\
\hline $25-30$ & 61 & 6.1 \\
\hline Median Age (IQR) & $21(20,22)$ & \\
\hline Mean (SD) & $21.7(2.3)$ & \\
\hline \multicolumn{3}{|l|}{ Year of study } \\
\hline Year 1 & 319 & 31.7 \\
\hline Year 2 & 389 & 38.6 \\
\hline Year 3+ & 298 & 29.6 \\
\hline \multicolumn{3}{|l|}{ Religion } \\
\hline Catholics & 339 & 33.6 \\
\hline Protestants & 390 & 38.7 \\
\hline Muslim & 90 & 8.9 \\
\hline Evangelical/SDA & 189 & 18.8 \\
\hline \multicolumn{3}{|l|}{ Marital status } \\
\hline Not married & 878 & 87.5 \\
\hline Consensual (Co-habiting) & 93 & 9.3 \\
\hline Married & 33 & 3.3 \\
\hline \multicolumn{3}{|l|}{ Residence } \\
\hline Home & 288 & 28.6 \\
\hline Hall on Campus & 188 & 18.7 \\
\hline Hostel & 368 & 36.6 \\
\hline Other arrangements & 162 & 16.1 \\
\hline \multicolumn{3}{|l|}{ Hall Assignment } \\
\hline Africa & 327 & 32.6 \\
\hline CCE & 309 & 30.8 \\
\hline Mary Stuart & 368 & 36.7 \\
\hline Africa & 327 & 32.6 \\
\hline
\end{tabular}

Note: * may vary because of missing values in some variables were resident in hostels, followed by homes (28.6\%), and only $18 \%$ were staying at the halls of residence at the university campus.

\section{Knowledge of contraceptive and sexual reproductive health}

Table 2 shows Percentage distributions of Knowledge of Contraceptive Methods and Sexual Reproductive Health. Knowledge of contraceptives was nearly universal (99.6\%). The most commonly known modern methods were pills $(86.7 \%)$ and male condoms (88.4 \%), followed by injectables (50.3\%), IUDs (35\%) and implants (26.7\%), female condom (22.1\%), while withdraw (34.2\%) was the most commonly mentioned traditional methods. The commonest sources of contraceptives were Hospitals (government, $64.3 \%$; private, $53.6 \%$ ), clinics (general $24 \%$, or Contraceptives $27.4 \%$ ) and pharmacy/drugs shops (36 \%). The level of knowledge was also very high regarding sexually transmitted infections (98.7\%), HIV/AIDS (99.3\%) and prevention of HIV/AIDs (98.8 \%) as well as its treatment (96\%). However, the proportions of students who knew about availability of treatment for HIV and STIs within their environs was low; $44.2 \%$ and $59.2 \%$ respectively.

\section{Perceptions and attitudes towards contraceptive methods by year of study}

Table 3 shows perceptions and attitudes towards contraceptive methods by year of study. Overall, nearly a quarter $(23.6 \%)$ perceived that modern contraceptive services and commodities were not accessible, or that it is not easy to discuss sexual matters with partner (24.4\%). About one in five students perceived that contraceptives were not for poor people $(21.3 \%)$ or that it is wrong to use contraceptives $(20.1 \%)$. However, only $6 \%$ believed that contraceptives were for females only. Attitudes to contraceptives being acceptable in the student community (93\%), being beneficial for males too (97.8\%), and couple counseling being able to increase male involvement in contraceptive use (96.2 \%) were highly rated as "agreed". All assessed perceptions and attitudes did not significantly differ by year of study.

\section{Contraceptive use, sexual behavior and pregnancy}

Table 4 shows contraceptive use, sexual behavior and pregnancy rates. Overall half $(51.2 \%)$ of the students were currently in sexual relationships, with slight increments in the proportions across the year of study. Nearly $70 \%$ had ever engaged in sexual intercourse while $62.1 \%$ reported sexual intercourse in the past 12 months. Over half $(55.1 \%)$ had ever used any method to prevent pregnancy while only $46.6 \%$ were currently using contraceptives with male condoms being the most commonly mentioned methods used (34.5\%). Ever being pregnant or knowledge of a pregnant friend significantly varied by year 
Table 2 Percentage distributions of Knowledge of Contraceptive Methods and Sexual Reproductive Health

\begin{tabular}{|c|c|c|c|c|c|}
\hline & & & Year-1 & Year-2 & Year 3+ \\
\hline Number & $1003+$ & & 319 & 389 & 298 \\
\hline Ever heard of contraceptive & Number & Percent "yes", (\%) & & & \\
\hline Yes & 999 & 99.6 & & & \\
\hline \multicolumn{6}{|l|}{ Contraceptive methods known } \\
\hline \multicolumn{6}{|l|}{ Modern } \\
\hline Tubal ligation & 99 & 9.8 & 7.5 & 9.3 & 13.1 \\
\hline Vasectomy & 99 & 9.8 & 8.2 & 9.5 & 12.1 \\
\hline Pill & 874 & 86.7 & 87.1 & 86.1 & 86.9 \\
\hline IUD & 353 & 35.0 & 26.3 & 35.5 & 43.6 \\
\hline Injection & 507 & 50.3 & 48.3 & 49.4 & 53.7 \\
\hline Implants & 269 & 26.7 & 18.2 & 29.8 & 31.9 \\
\hline Male condoms & 891 & 88.4 & 88.4 & 87.1 & 90.3 \\
\hline Female condoms & 223 & 22.1 & 18.5 & 21.1 & 27.5 \\
\hline Diaphragm & 74 & 7.3 & 5.6 & 5.7 & 11.4 \\
\hline Foam & 35 & 3.5 & 2.5 & 2.1 & 6.4 \\
\hline \multicolumn{6}{|l|}{ Traditional } \\
\hline Lactational Amenorrhea & 36 & 3.6 & 1.9 & 3.1 & 6.0 \\
\hline Rhythm/moon beads & 103 & 10.2 & 9.7 & 10.0 & 11.1 \\
\hline Withdrawal & 345 & 34.2 & 31.0 & 36.2 & 35.6 \\
\hline \multicolumn{6}{|l|}{ Know source of contraceptives } \\
\hline No & 30 & $9(3.0)$ & & & \\
\hline Yes & 961 & $932(97.0)$ & 96.2 & 97.9 & 96.6 \\
\hline \multicolumn{6}{|l|}{ Government } \\
\hline Hospital & 648 & 64.3 & 61.1 & 67.1 & 64.1 \\
\hline Health Centers & 242 & 24.0 & 26.0 & 25.7 & 19.8 \\
\hline Family planning clinic & 276 & 27.4 & 23.8 & 28.0 & 30.2 \\
\hline Outreach & 22 & 2.2 & 1.6 & 2.3 & 2.7 \\
\hline Community distributors & 41 & 4.1 & 4.4 & 4.4 & 3.4 \\
\hline \multicolumn{6}{|l|}{ Private providers } \\
\hline Hospital/clinic & 540 & 53.6 & 54.5 & 50.6 & 56.4 \\
\hline Pharmacy/Drug shop & 363 & 36.0 & 32.0 & 40.1 & 35.2 \\
\hline Midwife & 17 & 1.7 & 0.94 & 2.3 & 1.7 \\
\hline Outreaches & 20 & 2.0 & 0.94 & 3.1 & 1.7 \\
\hline NGO community based & 35 & 3.5 & 3.1 & 4.9 & 2.0 \\
\hline \multicolumn{6}{|l|}{ STIs Knowledge (yes) } \\
\hline Heard of STIs & 995 & 98.7 & 99.1 & 98.2 & 99.3 \\
\hline Knowledge of HIV/AIDS & 1,001 & 99.3 & 99.1 & 99.0 & 100 \\
\hline Knowledge of HIV prevention & 996 & 98.8 & 98.7 & 97.9 & 100 \\
\hline Heard about treatment of HIV & 968 & 96.0 & 93.7 & 96.1 & 98.3 \\
\hline Knowledge of HIV treatment availability & 445 & 44.2 & 41.4 & 45.0 & 45.6 \\
\hline Knowledge of STIs treatment availability & 597 & 59.2 & 53.9 & 60.9 & 62.4 \\
\hline Heard of VCT & 980 & 97.2 & 95.0 & 98.2 & 98.3 \\
\hline
\end{tabular}

†Number is less than 1008 because of 5 missing values on some variables, Percentage are row percent of each total number of respondents per variable 
Table 3 Perceptions and Attitudes Towards Contraceptive Methods by Year of study

\begin{tabular}{|c|c|c|c|c|c|}
\hline \multirow[b]{2}{*}{ Variable } & \multirow[b]{2}{*}{ Overall } & \multicolumn{3}{|c|}{ Year of study } & \multirow[b]{3}{*}{ P-values } \\
\hline & & Year -1 & Year-2 & Year-3+ & \\
\hline & $N(\%)^{*}$ & $N(\%)^{*}$ & $N(\%)^{*}$ & $N(\%)^{*}$ & \\
\hline \multicolumn{6}{|c|}{$\begin{array}{l}\text { Modern contraceptive services and commodities } \\
\text { are inaccessible }\end{array}$} \\
\hline Agree & $969(23.6)$ & $307(25.1)$ & $374(22.5)$ & $288(23.6)$ & 0.7289 \\
\hline \multicolumn{6}{|c|}{ Not easy to discuss sexual issues with partner } \\
\hline Agree & $684(24.4)$ & $184(27.2)$ & $274(25.5)$ & $226(20.8)$ & 0.2300 \\
\hline \multicolumn{6}{|c|}{$\begin{array}{l}\text { Couple counseling can improve male involvement } \\
\text { in contraceptive use }\end{array}$} \\
\hline Agree & $913(96.2)$ & $280(97.5)$ & $354(94.6)$ & $279(96.8)$ & 0.9499 \\
\hline \multicolumn{6}{|c|}{ Contraceptive are for females only } \\
\hline Agree & $971(6.1)$ & $308(6.5)$ & $376(4.8)$ & $287(7.3)$ & 0.7226 \\
\hline \multicolumn{6}{|c|}{$\begin{array}{l}\text { Contraceptives are acceptable in our University } \\
\text { community }\end{array}$} \\
\hline Agree & $975(93.0)$ & $309(94.8)$ & $377(94.4)$ & $289(89.3)$ & 0.6185 \\
\hline \multicolumn{6}{|c|}{ Contraceptives benefits males too } \\
\hline Agree & $989(97.8)$ & $311(96.7)$ & $386(98.4)$ & $292(97.9)$ & 0.8928 \\
\hline \multicolumn{6}{|c|}{ Contraceptives is not for the poor } \\
\hline Agree & $986(21.3)$ & $311(22.8)$ & $384(21.1)$ & $291(19.9)$ & 0.4829 \\
\hline \multicolumn{6}{|c|}{ It is wrong to use contraceptives } \\
\hline Agree & $989(20.4)$ & $314(20.1)$ & $383(20.6)$ & $292(20.5)$ & 0.9019 \\
\hline
\end{tabular}

${ }^{*} \mathrm{~N}=$ Total number of respondents with information on each variable, while $\%=$ percentage of respondents with "Agree" for each variable

of study; overall, $9 \%$ reported ever being pregnant, $4.1 \%$ (year-1), $9.8 \%$ (year2) and 13.1\% (year3+); $(\mathrm{p}=0.003)$ while a third (33.8 \%) knew of a pregnant friend $16.3 \%$ (year-1), $38.9 \%$ (year2) and $46.0 \%$ (year3+), p $<0.001$. Only $2 \%$ of students reported being pregnant; higher among year $3+$ compared to those in year-1. About $40 \%$ of ever pregnant respondents reported ever trying to terminate a pregnancy.

\section{Current contraceptive use by sexual active students}

Figure 1 shows distribution of current contraceptive use by year of study. Among the sexually active students, male condoms $58 \%,(n=363)$ or other modern contraceptives $15 \%(\mathrm{n}=93)$ where the most commonly mentioned methods, while $6 \%(n=37)$ only reported use of a traditional method. This pattern was similar across year of study. Although respondents were sexually active, about 1 in $5(22 \%)$ did not use any contraceptive, and this was most common in year-3+ $(27.5 \%)$ compared to either year 1 (18.4\%) or year 2 (18.3\%).

\section{Factors associated with contraceptive use}

Table 5 shows the modified Poisson multivariable regression analysis of factors associated with contraceptive use. Compared to year- 1 , year- 2 had a $22 \%$ higher prevalence of contraceptive use. Contraceptive use was $3 \%$ higher if a student was one year older than their counter-part adjusting for other factors.

The prevalence of contraceptive use was $75 \%$ higher among married compared to none married, and $35 \%$ lower in the Evangelical or SDAs compared to the Roman Catholic students. Perception of contraceptive methods being for females only was associated with a $41 \%$ higher prevalence of contraceptive use relative too those who disagreed, while students who perceived it as being wrong to use contraceptives has a $33 \%$ lower prevalence of use relative to those who had a favourable perception.

\section{Discussion}

The study assessed the knowledge, attitudes, perceptions and use of contraceptives among female undergraduate students of Makerere University. Our findings show that knowledge was universal, but contraceptive use was suboptimal. The most commonly known and used methods were the male condoms and oral pills, but knowledge of the female condom was very low. Positive perceptions and attitudes were strongest on couple counseling acceptability of contraceptives at the university and benefits of contraceptives to males. Negative perceptions about contraceptives being for the poor or their use being wrong were mentioned. High level of contraceptive knowledge does not translate into actual use in this study or from other studies $[14,15]$. Religious beliefs as evidenced by lower use 
Table 4 Contraceptive Use and Sexual Behaviors by Year of Study

\begin{tabular}{|c|c|c|c|c|c|}
\hline Variable & Overall & Year-1 & Year-2 & Year-3+ & P-values \\
\hline & $N(\%)^{* *}$ & $N(\%)^{* *}$ & $N(\%)^{* *}$ & $N(\%)^{* *}$ & \\
\hline \multicolumn{6}{|l|}{ Current Contraceptives use } \\
\hline Yes & $986(46.6)$ & $317(41.6)$ & $381(50.9)$ & $288(46.2)$ & 0.4643 \\
\hline \multicolumn{6}{|c|}{ Currently in sexual relationship } \\
\hline Yes & $1006(51.2)$ & $319(45.5)$ & $389(54.5)$ & $298(53.0)$ & 0.2730 \\
\hline \multicolumn{6}{|l|}{ Ever had sexual intercourse } \\
\hline Yes & $833(69.7)$ & $249(62.2)$ & $326(72.7)$ & $258(73.3)$ & 0.2588 \\
\hline \multicolumn{6}{|l|}{ Had sex in past 12 months } \\
\hline Yes & $850(62.1)$ & $261(55.9)$ & $326(65.6)$ & $263(63.9)$ & 0.3664 \\
\hline \multicolumn{6}{|c|}{ Ever used any method to prevent pregnancy } \\
\hline Yes & $985(55.1)$ & $312(47.4)$ & $376(58.8)$ & $297(58.6)$ & 0.1313 \\
\hline \multicolumn{6}{|l|}{ Current Contraceptives method } \\
\hline None & $527(53.4)$ & $185(58.4)$ & $187(49.1)$ & $155(53.8)$ & 0.5809 \\
\hline Traditional & $32(3.2)$ & $14(4.4)$ & $10(2.6)$ & $8(2.8)$ & 0.7053 \\
\hline Condoms-only & $340(34.5)$ & $98(30.9)$ & $149(39.1)$ & $93(32.3)$ & 0.8487 \\
\hline Modern with/out condoms & $87(8.8)$ & $20(6.3)$ & $35(9.2)$ & $32(11.1)$ & 0.4009 \\
\hline \multicolumn{6}{|l|}{ Know a pregnant friend } \\
\hline Yes & $1005(33.8)$ & $319(16.3)$ & $388(38.9)$ & $298(46.0)$ & $<0.001$ \\
\hline \multicolumn{6}{|l|}{ Ever been pregnant } \\
\hline Yes & $1004(9.0)$ & $318(4.1)$ & $388(9.8)$ & $298(13.1)$ & 0.0003 \\
\hline \multicolumn{6}{|c|}{ Ever tried to terminate pregnancy } \\
\hline Yes & $90(40.0)$ & $13(38.5)$ & 38 (36.8) & $39(43.6)$ & 0.7280 \\
\hline \multicolumn{6}{|c|}{${ }^{*}$ Currently pregnant (self-reported) } \\
\hline Yes & $1005(2.0)$ & $319(0.63)$ & $388(2.1)$ & $298(3.4)$ & 0.0174 \\
\hline
\end{tabular}

** * $\mathrm{N}=$ Total number of respondents with information on each variable, while $\%=$ percentage of respondents with "Agree" for each variable

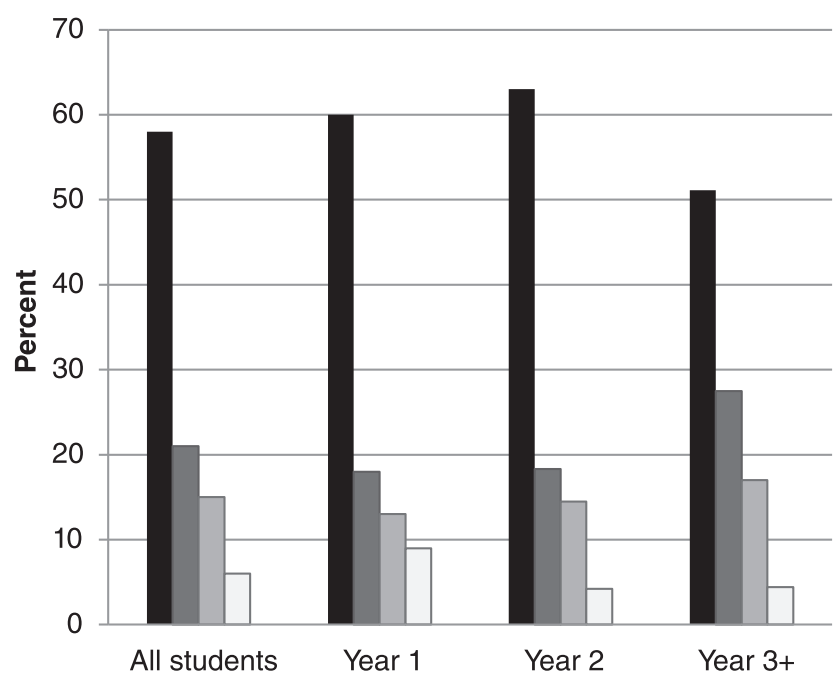

- Male Condoms Only

$\square$ None

$\square$ Other Modern Methods

$\square$ Traditional

Fig. 1 Current Use of Contraceptive Methods by 626 Sexually Active Students 
Table 5 Factors Associated with Modern Contraceptives Use Among Female University Students

\begin{tabular}{|c|c|c|c|}
\hline Variable & Crude PR (95 \% Cl) & Adjusted PR (95 \% Cl) & P-value \\
\hline \multicolumn{4}{|l|}{ Year of Study } \\
\hline Year-1 & 1.0 & 1.0 & \\
\hline Year-2 & $1.28(1.07,1.53)$ & $1.22(1.02,1.45)$ & 0.029 \\
\hline Year 3+ & $1.17(0.96,1.42)$ & $1.09(0.89,1.34)$ & 0.388 \\
\hline Age (years) & $1.05(1.04,1.08)$ & $1.03(1.00,1.06)$ & 0.027 \\
\hline \multicolumn{4}{|l|}{ Marital status } \\
\hline Not married & 1.0 & 1.0 & \\
\hline Consensual union & $1.91(1.65,2.21)$ & $1.75(1.50,2.05)$ & $<0.001$ \\
\hline Married & $1.84(1.43,2.36)$ & $1.32(0.92,1.90)$ & 0.132 \\
\hline \multicolumn{4}{|l|}{ Residence } \\
\hline Home & 1.0 & 1.0 & \\
\hline University hall & $0.80(0.62,1.02)$ & $0.84(0.65,1.07)$ & 0.161 \\
\hline Hostel & $1.07(0.90,1.28)$ & $1.08(0.91,1.28)$ & 0.392 \\
\hline Other arrangements & $1.23(0.99,1.51)$ & $1.06(0.87,1.29)$ & 0.566 \\
\hline \multicolumn{4}{|l|}{ Religion } \\
\hline Catholics & 1.0 & 1.0 & \\
\hline Protestants & $1.13(0.96,1.33)$ & $1.16(0.99,1.36)$ & 0.063 \\
\hline Muslim & $1.19(0.93,1.51)$ & $1.17(0.93,1.48)$ & 0.189 \\
\hline Evangelical/SDA & $0.62(039,0.50)$ & $0.65(0.50,0.84)$ & 0.001 \\
\hline \multicolumn{4}{|l|}{ Ever been pregnant } \\
\hline No & 1.0 & 1.0 & \\
\hline Yes & $1.66(1.39,1.98)$ & $1.18(0.93,1.48)$ & 0.166 \\
\hline \multicolumn{4}{|c|}{ Contraceptive methods are for females only } \\
\hline Disagree & 1.0 & 1.0 & \\
\hline Agree & $1.33(1.04,1.69)$ & $1.41(1.10,1.18)$ & 0.007 \\
\hline \multicolumn{4}{|c|}{ It is wrong to use contraceptives } \\
\hline Disagree & 1.0 & 1.0 & \\
\hline Agree & $0.67(0.54,0.84)$ & $0.67(0.55,0.83)$ & $<0.001$ \\
\hline
\end{tabular}

Bold type numbers indicate statistical significance at $<0.05$ level $P R$ :Prevalence ratio

of contraceptives by evangelicals or Seventh Day Adventist have a clear negative influence of utilization; this has also been shown in other university setting in western Uganda [16]. Religious and moral beliefs clearly overlap and need further exploration in a University setting.

The level of knowledge about contraceptives was found to be lower in similar African university settings, ranging $53.3 \%$ to $86.3 \%$ [17-21]. It is possible that even though students were universally aware of a range of contraceptive methods and knew where to get the services, they may have faced other obstacles that we did not directly measure in our study. For example, previous studies done in Uganda have highlighted social-cultural factors as critical barriers to contraceptive use in young females [15, 22]. Nalwadda and colleagues (2010) conducted a study in rural Uganda that specifically showed that societal norms such as condemning early engagement in sex, pregnancy and use of contraceptives among young unmarried girls presents a major obstacle to contraceptive use [23]. In our urban-based study, similar socio-cultural factors still have a lot influences leading to poor uptake of contraceptive among female students. In designing youth-friendly interventions it is imperative that efforts should be geared towards disseminating specific contraceptive information and education that is culturally-sensitive to the local setting.

Students knew the main sources of contraceptives services as government hospitals and private clinics but we did not verify if these were there major sources of contraceptive information. Awareness of sources was shown to reduce barriers and improve contraceptive use among female students in the University of Lesotho [1]. However, a 
study done in Ethiopia that evaluated major sources of information about contraceptives found out that a high knowledge of sources was not enough to result into actual use, rather the students needed more information about freely available contraceptive services [19, 24]. These observations suggest that reproductive health education programs should offer accurate and comprehensive information while building skills for negotiating safer sexual behaviours [7].

Overall the students had positive attitudes and perceptions towards using contraceptives. However, negative perceptions and attitudes existed about accessibility to contraceptive services; these included discussion of sexual issues with partner, contraceptives being for the poor and wrong perceptions about contraceptive use. A study in Nigeria reported that a high proportion of students perceived contraceptive use as bad because they believed it caused infertility [25]. However, studies have reported positive attitudes specifically toward emergency contraceptives among students at Jimma and Adama university in Ethiopia [26, 27] and negative attitudes toward emergency contraceptives increasing promiscuity in female students of Trinidad and Tobago [28].

Sexual activity among adolescents and young females is often associated with a greater risk for unintended pregnancies [2]. In our study, nearly $70 \%$ of the students were sexually active in the past 12 months. This finding supports results from the Uganda demographic health survey showing that premarital sex is common, with at least one in five young females aged 15-24 being sexually active [9]. Young females joining universities often become sexually active partly due to peer-pressures, alcohol use, or as result of a perceived sense of being in control of their social lives [26]. Similar levels of sexual activity were reported from other studies done among female university students of the same age group [29]. In contrast, some earlier studies done in Africa showed lower levels of sexual activity among university students, these ranged from $14 \%$ to 48 $\%[20,25,26,30,31]$. The differences in levels of sexual activity may be due to temporal events like increased sexual reproductive health over time or could be explained by differences in religious and cultural beliefs surrounding premarital sex [32].

Contraceptive use of any method among the university students was $46.6 \%$ which is nearly twice as high as the contraceptive prevalence of Uganda. On the other hand, the rate of use is lower than $79 \%$ contraceptive used among females that was reported from a study done in Mbarara University in Uganda [16] and in other university students in Lesotho, Kenya and Ethiopia [1, 14, 33]. Factors that were significantly associated with contraceptive use in this study are consistent with findings from a recent survey in a nationally representative in Ugandan women [22]. The high level of sexual activity and the risk of unintended pregnancies point to a need to promote sexual and reprodcutive health sevices in this setting. Male condoms were the most common contraceptive methods followed by oral pills among the sexually active students. Similar findings have been obseved elsewhere in both the developed [13,31,34] or developing countries $[1,25,27,28,35]$. However methods such as oral pills and injectable contraceptives have also been mentioned as being common in some settings such as Adama University, Ethiopia [27].

Among the sexually active students, one in five were engaging in unsafe sex suggesting high risk to unintended pregnancies and sexually transmitted diseases including HIV infection. Unsafe sexual practices are common among young adults especially in universities and other higher educational institutions [10, 11, 13]. The reported prevalence of unsafe sex may be higher in this setting if some students also use emergency contraceptives for prevention of pregnancy. Previous studies elsewhere have shown high level of unsafe sex [31,33] in similar settings. However, our study did not specifically evaluate the use of emergency contraceptives.

The prevalence of reported pregnancy at the time of survey was low (2\%) but probably under-reported due to associated stigma among unmarried pregnant women. However, $9 \%$ of the sexual active students reported being ever pregnant. Among the ever-pregnant females, $40 \%$ had ever tried to terminate the pregnancy suggesting a high level of both unmet need for contraceptive and unintended pregnancy in this setting. The reported $40 \%$ ever pregnant who tried to terminate a pregnancy may be an under estimate because abortion is illegal in Uganda, and can be very stigmatizing. Similar findings about abortion have been observed in Mexico public university among first year medical students where half (52\%) of the ever been pregnant female students performed unsafe abortions [36], and in Addis Ababa University Ethiopia 9 in $10(90 \%)$ of the ever pregnant students terminated their pregnancies with induced abortion [20].

\section{Study strengths and limitations}

Although the findings from this study are consistent with results from other university settings, we encountered some limitations. The planned random sampling based on the sampling frame from the University's academic registrar was dropped in favor of convenience sampling. However, interviewers were assigned/stationed at multiple academic units and asked to as much as possible randomly select participants without any specific characteristics. Some of the information especially on issues such as abortion may be under-reported because abortion is illegal and stigmatizing. Also pregnancy among unmarried females is culturally unacceptable thus leading to a potential for under-reporting. However, the study team 
recruited and trained experienced interviewers within the age range of the respondents as a way of minimizing reporting bias. The consistence in the contraceptive use indicators with other studies and the nationally representative samples such as the Uganda demographical and health surveys provide credence and strength to findings observed in this study.

\section{Conclusions}

Knowledge, perceived acceptability and benefits of contraceptive use were nearly universal, but contraceptive use was suboptimal in this setting. Ever trying to terminate a pregnancy was common and a clear indicator of unintended pregnancies. Religious beliefs and misconceptions of need for contraceptive are key determinants of poor uptake of contraceptives.

\section{Recommendations}

Interventions that promote translation of knowledge into proper sexual and reproductive health practices are urgently needed. The high rate of unintended pregnancy as measured by ever-attempt to terminate a pregnancy needs to be addressed through increased counseling and information about contraceptives, and accessible and of contraceptive services to students who desire to use them.

Religious leaders may have to be engaged to discuss issues of sexual and reproductive health and how to avert the unintended pregnancies. The leadership of evangelical and SDA faith can be an important stakeholder in this endeavor.

\section{Competing interests}

The authors declare that they have no competing interests.

\section{Authors' contribution}

$\mathrm{HN}$ : Designed the study, coordinated recruitment of participants and assured quality of data collection, participated in data analysis, and in writing of all drafts and the final manuscript JNS: Designed the study, coordinated recruitment of participants and assured quality of data collection, participated in data analysis and in writing of all drafts and the final manuscript. HS: Designed the study, participated in data analysis, and writing of drafts and the final manuscript. FEM: Participated in study design, led data analysis, and manuscript writing. All authors read and approved the final manuscript.

\section{Authors' information}

Henry Nsubuga and Juliet N. Sekandi shared first authorship.

\section{Acknowledgements}

The work was supported by a grant from The Family Health Research and Development Centre (FHRDC) Uganda Supported by Bill \& Melinda Gates Institute for Population \& Reproductive Health, Johns Hopkins Bloomberg School of Public Health, Baltimore, Maryland, USA. We thank the study participants and acknowledge the team of research assistants and the staff at the Makerere University, Counseling and Guidance Centre. We are grateful for the administrative support from Ms. Christine Muhumuza, the center Coordinator, FHRDC.

\section{Author details}

'Makerere University, Counseling and Guidance Centre, Kampala, Uganda. ${ }^{2}$ Makerere University, College of Health Sciences, School of Public Health, Kampala, Uganda. ${ }^{3}$ Department of Epidemiology and Biostatistics, College of Public Health, University of Georgia, Athens, Georgia, USA.

Received: 29 April 2015 Accepted: 23 January 2016

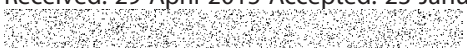

\section{References}

1. Akintade OL, Pengpid S, Peltzer K. Awareness and use of and barriers to family planning services among female university students in Lesotho. South African Journal of Obstetrics and Gynaecology. 2011;17(2):36-42.

2. Summers C, Guttmacher Institute. Unintended Pregnancy and Abortion in Uganda; 2013. https://www.guttmacher.org/presentations/unintendedpregnancy-abortion-Uganda.pdf downloaded January 262015.

3. World Health Organisation: Making Pregnancy Safer: Annual Report 2007. In.: World Health Organization, Geneva; 2008.

4. Cleland J, Bernstein S, Ezeh A, Faundes A, Glasier A, Innis J. Family planning: the unfinished agenda. Lancet. 2006;368(9549):1810-27.

5. United Nations Population Fund: State of the world population 2004. The Cairo consensus at ten: population, reproductive health and the global effort to end poverty. In.: UNFPA, New York; 2004.

6. Hubacher D, Mavranezouli I, McGinn E. Unintended pregnancy in sub-Saharan Africa: magnitude of the problem and potential role of contraceptive implants to alleviate it. Contraception. 2008:78(1):73-8.

7. Bearinger LH, Sieving RE, Ferguson J, Sharma V. Global perspectives on the sexual and reproductive health of adolescents: patterns, prevention, and potential. Lancet. 2007;369(9568):1220-31.

8. Mensch BS, Grant MJ, Blanc AK. The changing context of sexual initiation in sub-Saharan Africa. Popul Dev Rev. 2006;32:699-727.

9. Uganda Bureau of Statistics (UBOS) and ICF International Inc. Uganda Demographic and Health Survey 2011. Kampala, Uganda: UBOS and Calverton, Maryland: ICF International Inc.; 2012.

10. Mayega RW: HIV/AIDS Sero-behavioral Survey in Six Universities in Uganda. In.: East Afrcian Community-African Medical and Research Foundation, AMREF; 2010.

11. Rutherford GW, Anglemyer A, Bagenda D, Muyonga M, Lindan CP, Barker JL, et al. University students and the risk of HIV and other sexually transmitted infections in Uganda: the Crane survey. International journal of adolescent medicine and health. 2014;26(2):209-15.

12. Orji EO, Adegbenro CA, Olalekan AW. Prevalence of sexual activity and family-planning use among undergraduates in Southwest Nigeria. Eur J Contracept Reprod Health Care. 2005:10(4):255-60.

13. Heisler $\mathrm{K}$ and Van Eron DM. "A descriptive study of undergraduate contraceptive attitudes among students at the University of New Hampshire". 2012. Honors Theses. Paper 8. http://scholars.unh.edu/cgi/ viewcontent.cgi?article $=1007 \&$ context=honors downloaded January 26 2016.

14. Ochako R, Mbondo M, Aloo S, Kaimenyi S, Thompson R, Temmerman M, et al. Barriers to modern contraceptive methods uptake among young women in Kenya: a qualitative study. BMC public health. 2015;15(1):118.

15. Agyei WK, Migadde M. Demographic and sociocultural factors influencing contraceptive use in Uganda. Journal of biosocial science. 1995;27(1):47-60.

16. Mehra D, Agardh A, Petterson KO, Ostergren PO. Non-use of contraception: determinants among Ugandan university students. Global health action. 2012;5:18599.

17. Somba M, Mbonile M, Obure J, Mahande M. Sexual behaviour, contraceptive knowledge and use among female undergraduates' students of Muhimbili and Dar es Salaam Universities, Tanzania: a cross-sectional study. BMC women's health. 2014;14(1):94.

18. Ijirigho MI. "Use of Reproductive Health Information on Contraception among Female Undergraduates of University of Ibadan". 2010. Library Philosophy and Practice (e-journal). Paper 360. http://digitalcommons.unl. edu/libphilprac/360 downloaded January 262016

19. Lenjisa UL, Ulfina D, Tamme E, Kaba G, Berehe H, et al. Knowledge and Practice of Emergency Contraceptives among Students at Ambo Techniques College Ethiopia. Reprod Syst Sex Disord. 2014;3:136. doi:10. 4172/2161-038X.1000136

20. Tolossa E, Meshesha B, Alemu Abajobir A. Assessment of level of knowledge and utilization of emergency contraception among female students of 
Hawassa University, south Ethiopia. Advances in Reproductive Sciences. 2013;1:51-6.

21. Hoque ME, Ghuman S. Knowledge, practices, and attitudes of emergency contraception among female university students in KwaZulu-Natal. South Africa PloS one. 2012;7(9), e46346.

22. Asiimwe JB, Ndugga P, Mushomi J, Manyenye Ntozi JP. Factors associated with modern contraceptive use among young and older women in Uganda; a comparative analysis. BMC public health. 2014;14:926.

23. Nalwadda G, Mirembe F, Byamugisha J, Faxelid E. Persistent high fertility in Uganda: young people recount obstacles and enabling factors to use of contraceptives. BMC public health. 2010;10:530.

24. Hooja N, Mital P. Knowledge, Attitude And Practices Relating To Emergency Contraception Among College Girls And Their Mothers. Internet Journal of Gynecology and Obstetrics. 2012 Volume 16 Number 1

25. Cadmus E, Owoaje E. Patterns Of Contraceptive Use Among Female Undergraduates In The University Of Ibadan, Nigeria. Internet Journal of Health. 2009 Volume 10 Number 2.

26. Tura G, Alemseged F, Dejene S. Risky Sexual Behavior and Predisposing Factors among Students of Jimma University, Ethiopia. Ethiopian journal of health sciences. 2012;22(3):170-80.

27. Tilahun D, Assefa T, Belachew T. Knowledge, attitude and practice of emergency contraceptives among adama university female students. Ethiopian journal of health sciences. 2010;20(3):195-202.

28. Parey B, Addison L, Mark JK, Maurice B, Tripathi V, Wahid S, et al, Knowledge, attitude and practice of emergency contraceptive pills among tertiary level students in Trinidad: a cross-sectional survey. The West Indian medical journal. 2010;59(6):650-5.

29. Moser AM, Reggiani C, Urbanetz A. [Risky sexual behavior among university students in health science courses]. Revista da Associacao Medica Brasileira. 2007;53(2):116-21.

30. Adinew YM, Worku AG, Mengesha ZB. Knowledge of reproductive and sexual rights among University students in Ethiopia: institution-based cross-sectional. BMC Int Health Hum Rights. 2013 Feb 13;13:12. doi: 10.1186/1472-698X-13-12.

31. Simbar M, Tehrani FR, Hashemi Z. Reproductive health knowledge, attitudes and practices of Iranian college students. Eastern Mediterranean health journal. 2005;11(5-6):888-97.

32. Srikanthan A, Reid RL. Religious and cultural influences on contraception J Obstet Gynaecol Can. 2008;30(2):129-37.

33. Erena GM, Kerbo AA. Unwanted pregnancy and associated factors among female students of Madawalabu University Bale Zone, Oromia Region south east, Ethiopia. Science Journal of Public Health. 2015;3(1):50-5.

34. Dinas K, Hatzipantelis E, Mavromatidis G, Zepiridis L, Tzafettas J. Knowledge and practice of contraception among Greek female medical students. Eur J Contracept Reprod Health Care. 2008;13(1):77-82.

35. Abiodun OM, Baloqun OR. Sexual activity and contraceptive use among young female students of tertiary educational institutions in Ilorin, Nigeria. Contraception. 2009;79(2):146-9.

36. Ortiz-Ortega A, De La Torre GG, Galvan F, Cravioto P, Paz F, Diaz-Olavarrieta C, et al. Abortion, contraceptive use, and adolescent pregnancy among first-year medical students at a major public university in Mexico City. Rev Panam Salud Publica. 2003;14(2):125-30.

\section{Submit your next manuscript to BioMed Central and we will help you at every step:}

- We accept pre-submission inquiries

- Our selector tool helps you to find the most relevant journal

- We provide round the clock customer support

- Convenient online submission

- Thorough peer review

- Inclusion in PubMed and all major indexing services

- Maximum visibility for your research

Submit your manuscript at www.biomedcentral.com/submit

C Biomed Central 